\title{
The Future is Here: Library Services for Mobile Devices
}

\section{Sally Wilson}

Ryerson University

digital.library.ryerson.ca/object/303

Please Cite:

Wilson, S. (2009). The future is here: Library services for mobile devices.

Access: Ontario Library Association, 15(4), 18-19.

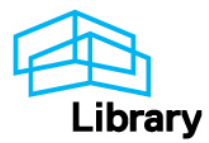


local libraries. Libraries with multiple branches might want to capitalize on the GPS function to create custom maps to branch locations.

Other services that make life easier for your users can also port well to mobile devices. Our users overwhelmingly indicated that they would like to be able to book study rooms on the go. This is not surprising as our regular study room booking service is heavily used - there were more than 17,000 bookings in the fall term. We implemented mobile booking recently and, in the fall of 2009, expect to see this become one of our more popular mobile services.

Even if you don't have the budget or the staff to implement a wide range of mobile services, there are some actions that you can take now. A mobile website of a few pages can be created quite easily. Most existing mobile library sites have a similar set of links to quick information - hours, news, mobile catalogue, workshops/programs, and contact information. Phone numbers are particularly relevant on mobile pages, as they can be made into links that when clicked automatically place the call.

These are just a few examples of library services for mobile devices. The increasing pervasiveness of mobile devices with internet access promises an exciting time for libraries as we adapt and extend existing services to these devices and explore opportunities for innovative new services.

Sally Wilson is Web Services Librarian at the Ryerson University Library. She obtained her master's degree in Library and Information Science from the University of Toronto.
Mobile Library Services:

Survey Results

Ryerson University Library

Mobile Device Survey Results

ryerson.ca/library/msurvey/

\section{Examples of Library}

Mobile Services

District of Columbia Public

Library iPhone software

dclibrarylabs.org/projects/iphone/

Denton Public Library

library.cityofdenton.com

University of Bath QR Code Example library.bath.ac.uk/uhtbin/bath/

UB-LIBS/ckey/1916692

Further Reading

On the Move with the Mobile Web:

Libraries and Mobile Technologies

By Ellyssa Kroski

alatechsource.org/ltr/on-the-movewith-the-mobile-web-librariesand-mobile-technologies

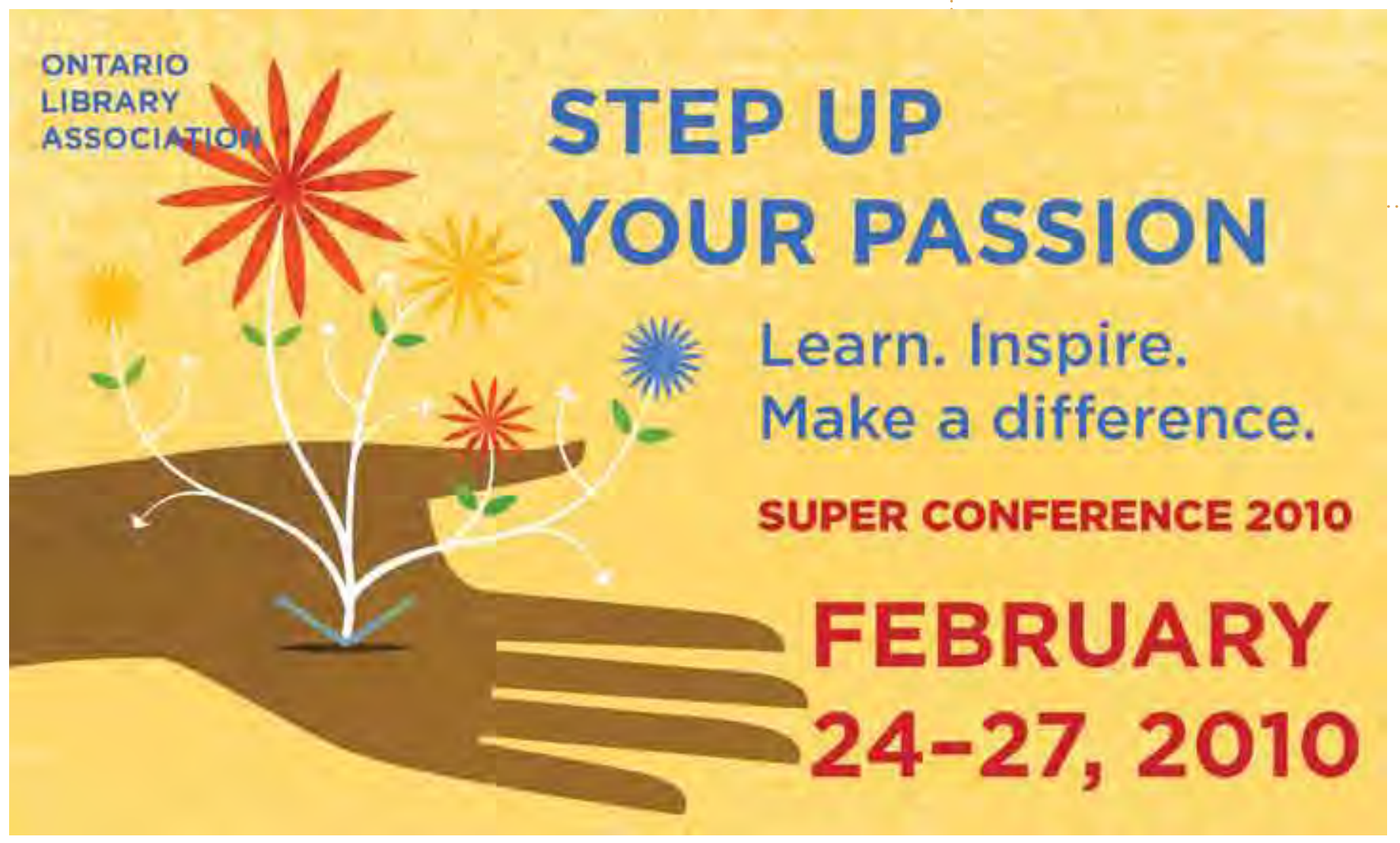

